\title{
Modelling the impact of mulching the soil with plant remains on water regime formation, crop yield and energy costs in agricultural ecosystems
}

\author{
Yeugeniy M. Gusev, Larisa Y. Dzhogan, and Olga N. Nasonova \\ Laboratory of Soil Water Physics, Institute of Water Problems, Russian Academy of Sciences, \\ 119333 Moscow, Russian Federation \\ Correspondence: Yeugeniy M. Gusev (sowaso@yandex.ru)
}

Received: 31 May 2017 - Accepted: 20 August 2017 - Published: 1 February 2018

\begin{abstract}
The model MULCH, developed by authors previously for simulating the formation of water regime in an agricultural field covered by straw mulch layer, has been used for the comparative evaluation of the efficiency of four agricultural cultivation technologies, which are usually used for wheat production in different regions of Russia and Ukraine. It simulates the dynamics of water budget components in a soil rooting zone at daily time step from the beginning of spring snowmelt to the beginning of the period with stable negative air temperatures. The model was designed for estimation of mulching efficiency in terms of increase in plant water supply and crop yield under climatic and soil conditions of the steppe and forest-steppe zones. It is used for studying the mulching effect on some characteristics of water regime and yield of winter wheat growing at specific sites located in semi-arid and arid regions of the steppe and forest-steppe zones of the eastern and southern parts of the East-European (Russian) plain. In addition, a previously developed technique for estimating the energetic efficiency of various agricultural technologies with accounting for their impact on changes in soil energy is applied for the comparative evaluation of the efficiency of four agricultural cultivation technologies, which are usually used for wheat production in different regions of the steppe and forest-steppe zones of the European Russia: (1) moldboard tillage of soil without irrigation, (2) moldboard tillage of soil with irrigation, (3) subsurface cultivation, and (4) subsurface cultivation with mulching the soil with plant remains.
\end{abstract}

\section{Introduction}

The present work considers the possibility of rational use of natural resources (water, soil, and energy), which are interconnected, in particular, through food-water-energy nexus. One of non-traditional agricultural technologies, which are developing in many countries and oriented on sustainable management, on conservation of soil, energy and water resources, as well as on protection of environment, is soil mulching, i.e. covering the soil surface with plant remains after previous harvesting. However, application of this agricultural technology is mainly based on an empirical approach without estimating its efficiency, which would allow one to systematize the obtained results and predict the implications of mulching (Scopel et al., 2004; Balwinder-Singha et al., 2016). This raises the problem of developing the universal technique for calculating an increase in water supply and yield of agroecosystems due to mulching as well as predicting the efficiency of mulching under different natural conditions. This work is intended to contribute to the solution of the stated problem. The aim of the present study is development of a technique for calculating the efficiency of soil mulching and application of the developed technique for agricultural fields located in the eastern and southern parts of the East-European (Russian) plain.

One more objective of the study is application of a previously developed technique for evaluating the energetic efficiency of different agricultural management practices with accounting for their effect on soil energy. Here, the technique is used for comparative evaluation of the efficiency of four agricultural technologies: (1) moldboard tillage without irrigation, (2) moldboard tillage with irrigation, (3) subsurface 
(a)

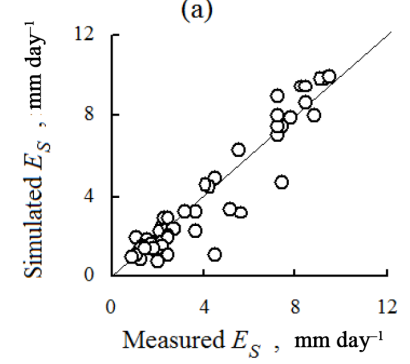

(c)
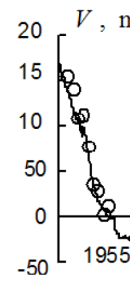

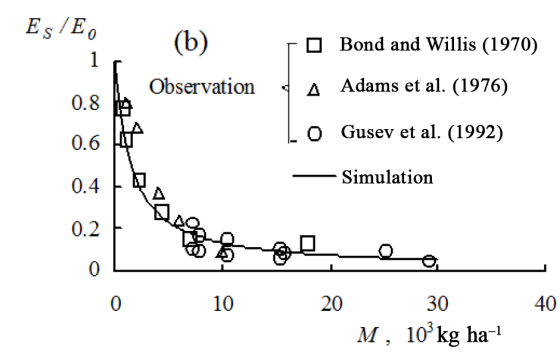

— Simulation

○ Observation

Figure 1. Model validation: (a) comparison of simulated daily bare soil evaporation and measured one at the Kursk Biospheric station (solid line is the 1: 1 line); (b) cumulative (for some rainless intervals) evaporation from bare soil covered with straw mulch vs. surface density of straw $M\left(E_{0}\right.$ is the potential bare soil evaporation without mulch cover); (c) dynamics of simulated and measured productive water storage $V$ in $1 \mathrm{~m}$ soil layer during the warm seasons (from April to October) in wheat fields at the Ershov agrometeorological station.

cultivation, and (4) subsurface cultivation with mulching the soil with plant remains, which are usually used for wheat production at different agrometeorological stations located in the steppe and forest-steppe zones of the European Russia.

\section{Brief description of the MULCH model}

Description of the MULCH model, which simulates the formation of water regime in an agricultural field covered with a straw mulch, is presented in (Gusev and Dzhogan, 2000; Gusev and Busarova, 2001; Gusev, 2012). The model calculates the dynamics of water budget components in a soil rooting layer (taken to be equal to $1 \mathrm{~m}$ ) at daily time step from the beginning of spring snowmelt to the beginning of the period with stable negative air temperatures. It treats the following processes: interception of precipitation by the mulch layer and subsequent evaporation, transpiration, evaporation from the soil under the mulch layer, water exchange with the underlying soil horizons, and changes in water storage of the sol rooting zone.

The model is intended for estimation of mulching efficiency in terms of increase in plant water supply and crop yield under different climatic and soil conditions.

Interception of precipitation by the mulch layer is evaluated using the so-called "bucket" concept. In so doing, the mulch serves as an intercepting reservoir of a constant capacity. Calculation of the water budget components within a soil-mulch-vegetation-atmosphere system is based on the solution of the following water budget equation:

$\frac{\mathrm{d} V}{\mathrm{~d} t}=P-\mathrm{ET}-Q-Y$,
$\mathrm{ET}=E_{\mathrm{T}}+E_{\mathrm{S}}+E_{\mathrm{m}}$,

where $t$ is the time, $V$ is the productive soil water storage in the soil rooting layer (equaled to the difference between the total soil water storage and plant wilting point), $P$ is the rainfall, ET is the evapotranspiration, $E_{\mathrm{T}}$ is the transpiration, $E_{\mathrm{S}}$ is the bare soil evaporation, $E_{\mathrm{m}}$ is the evaporation from the mulch layer, $Q$ is the water exchange at the lower boundary of the root zone, and $Y$ is the surface runoff. Technique for the calculation of the components $E_{\mathrm{T}}, E_{\mathrm{S}}$ and $E_{\mathrm{m}}$ is described in a number of publications (e.g. Budagovskii, 1989; Gusev, 1998; Gusev and Dzhogan, 2000).

Along with development of the calculational algorithm, preparation of input data represents an important stage of elaborating the model. Inputs for the MULCH model include (1) forcing data (precipitation, wind speed, air temperature and humidity, net radiation), (2) initial spring soil water storage, (3) soil hydrophysical parameters, (4) mulch parameters, and (5) type of vegetation.

\section{Validation of the MULCH model}

The validation of the MULCH model was performed using different experimental data. First of all, the ability of the model to reproduce bare soil evaporation $E_{\mathrm{S}}$ without mulch layer was investigated, because mulching substantially affects $E_{\mathrm{S}}$ and it is very important to be sure that $E_{\mathrm{S}}$ is simulated adequately. Figure 1a shows a comparison of simulated daily $E_{\mathrm{S}}$ with corresponding measured values. The measurements were performed by means of specific evaporometers at the Kursk Biospheric Station (Institute of Geography, Russian Academy of Sciences) located in the forest-steppe zone 


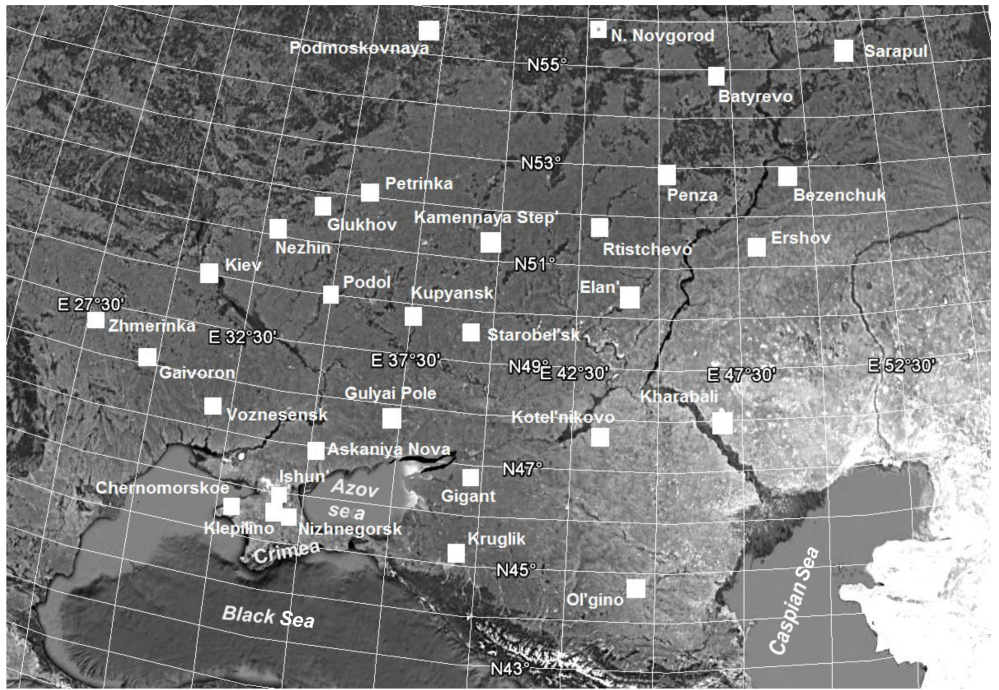

Figure 2. The study region (the southern part of the Russian Plain). The white squares are agrometeorological stations.

and characterized by a typical chernozem soil. The comparison of simulated and measured data demonstrates the possibility of application of the developed model for simulating bare soil evaporation.

At the next stage, the ability of the MULCH model to simulate evaporation from the soil covered with plant mulch under unlimited water supply (i.e. in the absence of dry layer at the soil surface) was investigated. Some results are given in Fig. 1b. The measurements were taken from literature (Bond and Willis, 1970; Adams et al., 1976) and obtained in our field experiments (Gusev et al., 1992).

Besides, the model was tested for agricultural ecosystems without mulch and while studying the mulching effect on some characteristics of the water regime and yield of winter wheat in several sites located in semi-arid and arid regions of the steppe and forest-steppe zones situated in the eastern and southern parts of the East-European (Russian) plain. An example of dynamics of soil water storage in $1 \mathrm{~m}$ soil layer without mulching as simulated by the MULCH model and measured at the agrometeorological station Yershov, which is located in the arid region of the steppe zone, is shown in Fig. 1c.

Analysis of the results of model validation allowed us to conclude that the proposed model can be used for the solution of the problem of estimating the efficiency of soil mulching in terms of increase in water supply of agricultural ecosystems.

\section{The study area and data}

In the present work, the territory under consideration includes the south of the European part of Russia, the Crimea and the south-eastern part of Ukraine (Fig. 2). This region situated in the steppe and forest-steppe zones is character- ized by arid and semi-arid climate. Therefore, the highest efficiency of mulching can be expected there. In such a region, as a rule, the summer surface runoff $Y$ and upward components of water exchange between the soil root zone and the underlying layers $Q$ can be neglected that allowed us to simplify the model and use the following equation instead of Eq. (1):

$$
\frac{\mathrm{d} V}{\mathrm{~d} t}=P-\mathrm{ET} .
$$

The records of standard observations from agrometeorological stations (Fig. 2) were used as meteorological forcing data and initial values of soil water storage. The soil hydrophysical parameters were also derived from the results of field studies performed at the stations. The dynamics of a leaf area index of wheat was calculated with the help of the model for its formation described in Gusev and Busarova (1998). This model suggests that evolution of the leaf area index of a specific crop during the vegetation period is determined by some preset ("genetic") program, dynamics of air temperature, and water regime of a soil root zone.

The parameters of mulch were determined during the field experiments (Gusev et al., 1992). It was found that the convective diffusivity of water vapor in a mulch layer is a function of the wind speed; the water-holding capacity of the mulch consisting of fresh plant remains can be taken as $1.8 \mathrm{~kg} \mathrm{~kg}^{-1}$. The surface density of the mulch layer, which also determines its depth under the given bulk density of straw (of about $15-20 \mathrm{~kg} \mathrm{~m}^{-3}$ ), is a varying parameter, which depends on the facilities at each farm. It can reach 0.1$1.0 \mathrm{~kg} \mathrm{~m}^{-2}$, which results in ranging of the depth of a mulch layer between 0.5 and $5.0 \mathrm{~cm}$ at the given bulk density of straw. 


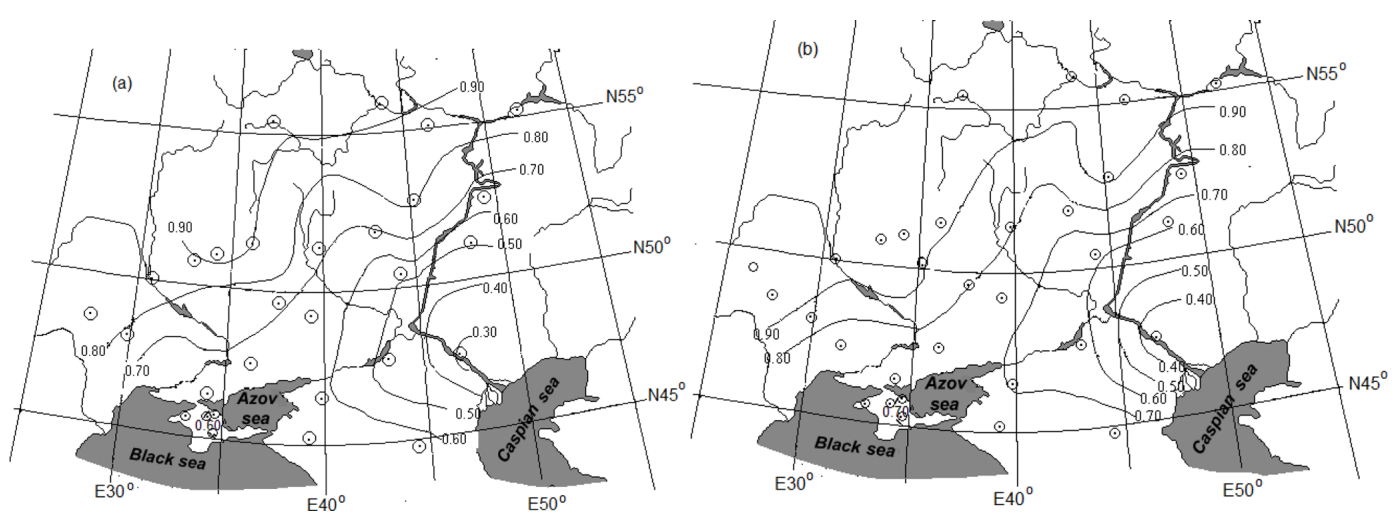

Figure 3. Distribution of many-year averages of the index of plant water supply $\eta_{\mathrm{W}}$ (a) without mulching the agricultural fields and (b) in the case of soil mulching.

\section{Indexes of plant water supply in agroecosystems}

The following indexes can be used for comparison of changes in water regime of agricultural system due to influence of different agrotechnologies (Budagovskii, 1985; Gusev and Novak, 2007):

$\eta_{\mathrm{w}}=E_{\mathrm{T}} / E_{\mathrm{TP}}$

$\eta_{\mathrm{e}}=E_{\mathrm{T}} / \mathrm{ET}$,

where $E_{\mathrm{TP}}$ is the potential transpiration, ET is the evapotranspiration. The former index (Eq. 4) characterises plant water supply, while the latter one (Eq. 5) can be treated as an efficiency of utilization of soil water resources by vegetation. Calculation of these indexes is based on the modelling of water exchange processes within a soil-mulch-vegetationatmosphere system (Gusev and Dzhogan, 2000). To determine the efficiency of soil mulching these indexes and winter wheat yield were calculated both in the presence and absence of mulch layer.

\section{Estimates of the efficiency of mulching}

A comparison of the indexes of crop water supply and the difference in crop yield in the presence and absence of mulch layer made it impossible to evaluate the efficiency of mulching. Model simulations were performed for 2025 years for winter wheat. Analysis of the results showed that mulching results in noticeable changes in water regime of agricultural fields and crops yield until the thickness of mulch layer reaches $4-5 \mathrm{~cm}$. Further increase in the mulch thickness does not practically influence these characteristics. Thus, there is some optimal thickness of the mulch layer $(\sim 5 \mathrm{~cm})$, which allows one to improve plant water supply and increase crop yield. This is why, in further analysis, the thickness of mulch layers is taken to be equal to $5 \mathrm{~cm}$.

The performed calculations made it possible to illustrate the spatial distribution of plant water supply $\eta_{\mathrm{w}}$ in the case of application of modern technology of cultivation of winter wheat both in the absence of mulching (Fig. 3a) and with mulching (Fig. 3b). (The limited volume of the article does not allow us to consider the index $\eta_{\mathrm{e}}$.) As can be seen in Fig. 3a, the index $\eta_{\mathrm{w}}$ has a pronounced tendency to decrease towards the southeast and varies from 0.90 to 0.30 over the territory when a traditional agrotechnology is used. In the most important for wheat production forest-steppe and steppe regions, it equals to $0.60-0.70$ and $0.70-0.80$ in the Russian and in the Ukrainian part of the region, respectively. Application of the mulch layer leads to increase in $\eta_{\mathrm{w}}$ by 10 $15 \%$. Such an increase is very important, in particular, for the steppe part of Crimea, because in 2014 the Ukrainian government blocked the North-Crimean Channel, which largely provided irrigation for agroecosystems.

Figure 4 shows a spatial distribution of mean increase in winter wheat yield due to mulching. As can be seen in Fig. 4, in the forest-steppe and steppe zones the increase mainly equals to $3-5$ centner ha ${ }^{-1}$, changing from 67 centner ha ${ }^{-1}$ in the more humid north-western and northern areas to 2 centner ha ${ }^{-1}$ in the southern arid regions. Experimental estimates of the impact of mulching on the yield of cereals are very limited. More reliable data are given in Lomakin (1988). According to Lomakin (1988), the increase in the yield of grain crops equals, on average, to 4.5 centner ha $^{-1}$ in Petrinka (see its location in Fig. 2) that is in a good agreement with our results.

\section{Energetic criteria of the efficiency of agricultural technologies}

In addition, the energetic efficiency of various agricultural technologies, such as: (1) mouldboard tillage of soil without irrigation, (2) mouldboard tillage of soil with irrigation, (3) subsurface (reduced) cultivation, and (4) subsurface cultivation with mulching the soil with plant remains, was estimated using a technique developed in Gusev and Busarova (2001). These agricultural cultivation technologies 


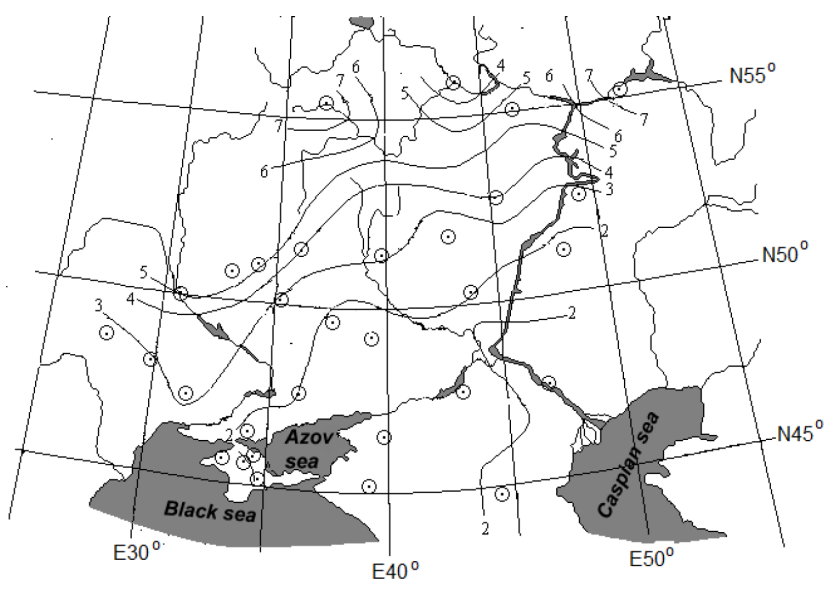

Figure 4. The increase in many-year averages of winter wheat productivity (in centner ha ${ }^{-1}$ ) due to mulching the soil with plant remains.

are usually used for wheat production in different regions of the steppe and forest-steppe zones of the European part of Russia. In so doing, impact of these technologies on soil energy was also taken into account, because agricultural technologies result in changes in the content of organic matter (humus) in the soil. The content of humus largely determining soil fertility and influencing a primary organic production is directly connected with soil energy. Thus, to estimate the efficiency of an agricultural technology, it is necessary to add a component describing changes in soil energy to an energetic criterion used for comparison of agrotechnologies:

$K=\frac{\mathrm{En}_{\mathrm{out}}+\Delta \mathrm{En}_{\mathrm{s}}}{\mathrm{En}_{\text {in }}}$,

where $\mathrm{En}_{\text {in }}$ is incoming energy from various anthropogenic sources, $\mathrm{En}_{\text {out }}$ is the output energy of yield in the form of chemical energy of food and raw organic matter, $\Delta \mathrm{En}_{\mathrm{s}}$ is the change in soil energy during a corresponding time interval (for example, a year). The total anthropogenic energy $\mathrm{En}_{\text {in }}$ consists of energetic expenses for crop production and ingathering, for manufacture and operation of engineering and equipment, their amortization, for capital investments, irrigation, production of fuel, mineral fertilizers, etc.

The technique for estimating all energetic components in Eq. (6) was developed in Gusev and Busarova (2001). Here, we give an example of estimation of $K$ for comparison of the abovementioned agricultural tillage modes, which were used for wheat production at four agrometeorological stations located in the European part of Russia: Petrinka, Kamennaya Step', Bezenchuk, and Ershov (Fig. 5).

The obtained estimates of the energetic efficiencies of the tillage modes allowed us to conclude that mulching the soil with plant remains in combination with reduced (subsurface) cultivation is the most effective agricultural mode for the regions under study. This technology can be considered as the

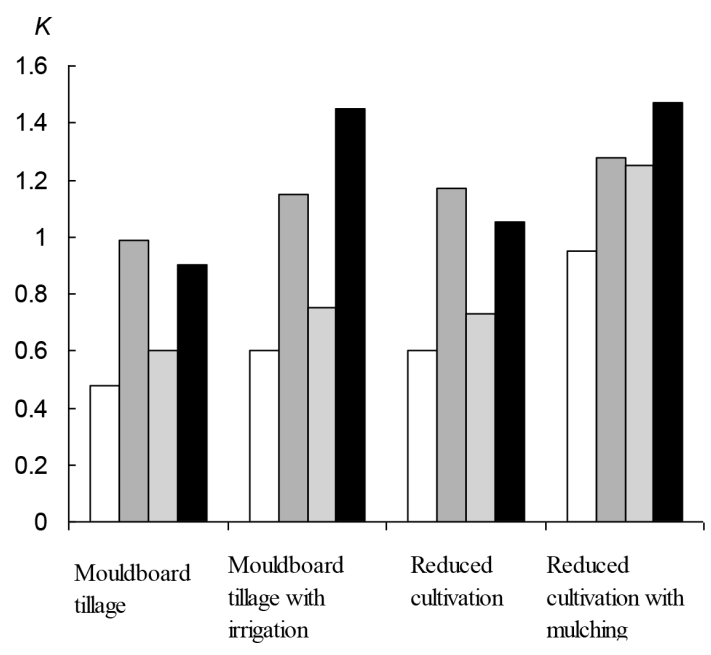

Figure 5. Energetic efficiency of various tillage modes with taking into account the change in soil energy for wheat production at the following agrometeorological stations: Ershov (empty boxes), Bezenchuk (dark grey boxes), Kamennaya Step' (light grey boxes), and Petrinka (black boxes).

most promising for the development of agriculture at least in these regions of Russia.

In Kolganov et al. (2016) it is believed that about $10 \%$ of arable land in water-deficit and arid regions of Russia need to be irrigated to provide higher and more stable yields in agriculture (these regions are considered in the present paper). Currently, approximately $4.2 \%$ of arable land in Russia is irrigated.

We have considered two techniques for increasing yields of wheat for the Russian part of the region (including the Crimea), considered in the present paper: (1) increasing the share of irrigated land in the region to by $10 \%$, (2) obtaining the same annual gross yield on the same arable land, using the reduced cultivation with mulching (instead of increasing irrigated areas). It turned out that the same (for the two considered techniques) annual gross yields of wheat $\left(6.5 \times 10^{8} \mathrm{GJ} \mathrm{yr}^{-1}\right.$, this is equivalent to the yield of grain of $\sim 43$ million $\mathrm{yr}^{-1}$ ) are obtained if in the second case the reduced cultivation with mulching is used for $30 \%$ of arable land. Herewith the annual energetic costs in the second case are less than in the first case by $10^{8} \mathrm{GJ} \mathrm{yr}^{-1}$. If this difference in energy costs is translated into the cost of the volume of oil (with the same energy content), then, at an oil price of nearly USD 50 per barrel, the second technique is cheaper than the first one approximately by USD 1 billion $\mathrm{yr}^{-1}$.

\section{Conclusion}

1. The MULCH model describing formation of the water regime of agroecosystems allows one to estimate the impact of soil mulching on plant water supply and crop yield. The model was applied for estimating the effi- 
ciency of mulching the winter wheat fields located in the eastern and southern parts of the East-European (Russian) plain.

2. It is shown that mulching with plant remains results in noticeable changes in water supply and yield of winter wheat only if the thickness of mulch layer is within $4-5 \mathrm{~cm}$. Further increase in the thickness does not practically influence these characteristics.

3. Mulching with plant remains leads to increase in the ratio of actual transpiration to potential one, on average, by $10-15 \%$ over the study area. At the same time the increase in the yield of winter wheat is $3-5$ centner ha ${ }^{-1}$ for most of the territory varying from 6-7 centner ha ${ }^{-1}$ in more humid north-western and northern regions to 2 centner ha ${ }^{-1}$ in arid southern areas.

4. The obtained estimations of energetic efficiency for the four tillage modes usually used for wheat production allow us to conclude that soil mulching with plant remains in combination with subsurface cultivation is the most efficient agricultural mode for the regions of the steppe and forest-steppe zones of the East-European (Russian) plain. This technology can be considered as the most promising for development of agriculture in these regions, because it does not require an increase in traditional resources (for example, irrigation) used there.

Data availability. Observations from agrometeorological stations can be taken from the Russian Research Institute of Hydrometeorological Information - World Data Center (RIHMI-WDC) (http: //meteo.ru).

Competing interests. The authors declare that they have no conflict of interest.

Special issue statement. This article is part of the special issue "Water security and the food-water-energy nexus: drivers, responses and feedbacks at local to global scales". It is a result of the IAHS Scientific Assembly 2017, Port Elizabeth, South Africa, 10-14 July 2017.

Acknowledgements. The study related to the eastern and southern parts of the East-European (Russian) plain was supported by the Russian Science Foundation (grant no. 16-17-10039), the study related to the Crimea was supported by the Russian Academy of Sciences.
Edited by: Barry Croke

Reviewed by: two anonymous referees

\section{References}

Adams, J. E., Arkin, G. F., and Ritchie, J. T.: Influence of row spacing and straw mulch on first stage drying, Soil Sci. Soc. Am. J., 40, 436-442, 1976.

Balwinder-Singha, Humphreysb, E., Gaydond, D. S., and Eberbachf P. L.: Evaluation of the effects of mulch on optimum sowing date and irrigation management of zero till wheat in central Punjab, India using APSIM, Field Crops Res., 197, 83-96, 2016.

Bond, J. J. and Willis, W. O.: Soil water evaporation: first stage drying as influenced by surface residue and evaporation potential, Soil Sci. Soc. Am. Proc., 34, 924-928, 1970.

Budagovskii, A. I.: Soil water reserves and the water supply of plant cover, Vodn. Res., 4, 3-13, 1985.

Budagovskii, A. I.: Main principles of calculation of irrigation rates and irrigation regimes, Vodn. Res., 1, 38-48, 1989.

Gusev, E.: Soil water resources and ecology of terrestrial vegetation cover. Conceptions, experiment, calculations, Palmarium Academic Publishing, Saarbrücken, 2012.

Gusev, E. M.: Evaporation from soil under drying, Euras. Soil Sci., 8, 836-840, 1998.

Gusev, E. M. and Busarova, O. E.: Modeling the dynamics of the leaf area index for grain crops, Russ. Meteorol. Hydrol., 1, 7075, 1998.

Gusev, E. M. and Busarova, O. E.: Evaluating the energy efficiency of agricultural technologies, Euras. Soil Sci., 34, 741-751, 2001.

Gusev, E. M. and Dzhogan, L. Y.: Evaluation of the effect of soil mulching with plant residues on the water regime of agroecosystems, Euras. Soil Sci., 11, 1238-1247, 2000.

Gusev, E. M., Busarova, O. E., Shurkhno, A. A., and Yasinskii, S. V.: The effect of straw mulch on the thermal regime of soil after snow melting, Pochvovedenie, 5, 49-59, 1992.

Gusev, Y. and Novák, V.: Soil water - main water resources for terrestrial ecosystems of the biosphere, J. Hydrol. Hydromech., 55, 3-15, 2007.

Kolganov, A. V., Suhoi, N. V., Shkura, V. N., and Shchedrin, V. N.: The development of reclamation of agricultural land in Russia, RosNIIPM, Novocherkassk, 2016.

Lomakin, M. M.: Mulch Soil Tillage on Slope, Agropromizdat, Moscow, 1988.

Scopel, E., Da Silva, F., Corbeels, M., Affholder, F., and Maraux, F.: Modelling crop residue mulching effects on water use and production of maize under semi-arid and humid tropical conditions, Agronomie, 24, 383-395, 2004. 